\title{
BMJ Open Socioeconomic circumstances and respiratory function from childhood to early adulthood: a systematic review and meta-analysis
}

\author{
Vânia Rocha, ${ }^{\oplus 1}$ Sara Soares, ${ }^{1}$ Silvia Stringhini, ${ }^{2,3}$ Sílvia Fraga ${ }^{1,4}$
}

To cite: Rocha V, Soares S, Stringhini S, et al.

Socioeconomic circumstances and respiratory function from childhood to early adulthood: a systematic review and meta-analysis. BMJ Open 2019;9:e027528. doi:10.1136/ bmjopen-2018-027528

- Prepublication history and additional material for this paper are available online. To view please visit the journal online (http://dx.doi.org/10.1136/ bmjopen-2018-027528).

Received 2 November 2018

Revised 11 April 2019

Accepted 22 May 2019

\section{Check for updates}

(c) Author(s) (or their employer(s)) 2019. Re-use permitted under CC BY-NC. No commercial re-use. See rights and permissions. Published by BMJ.

${ }^{1}$ EPIUnit, Instituto de Saúde Pública, Universidade do Porto, Porto, Portugal

${ }^{2}$ Institute of Social and

Preventive Medicine, University Hospital of Lausanne, Lausanne, Switzerland

${ }^{3}$ Population Epidemiology Unit, Primary Care Division, Geneva University Hospitals, Geneva, Switzerland

${ }^{4}$ Departamento de Ciências da Saúde Pública e Forenses e

Educação Médica, Universidade do Porto Faculdade de Medicina, Porto, Portugal

Correspondence to

Vânia Rocha;

vania.rocha@ispup.up.pt

\section{ABSTRACT}

Objective Disadvantaged socioeconomic circumstances in early life have the potential to impact lung function. Thus, this study aimed to summarise evidence on the association between socioeconomic circumstances and respiratory function from childhood to young adulthood. Design Systematic review and meta-analysis. Methods Following the Preferred Reporting Items for Systematic Review and Meta-analysis guidelines, Medline, ISI-Web of Science and Scopus were searched from inception up to January 2018. Original studies on the association between socioeconomic circumstances and respiratory function in early ages (ie, participants younger than 25 years of age) were investigated. Two investigators independently evaluated articles, applied the exclusion criteria, extracted data and assessed the risk of bias using the Newcastle-0ttawa Scale. A metaanalysis of the standardised mean difference and $95 \% \mathrm{Cl}$ in respiratory function between participants from different socioeconomic circumstances was conducted, using a random-effects model.

Results Thirty-three papers were included in this review and 23 showed that disadvantaged socioeconomic circumstances were significantly associated with reduced respiratory function. The meta-analysis including seven papers showed a significant difference of -0.31 (95\% $\mathrm{Cl}-0.42$ to -0.21 ) litres in forced expiratory volume in the first second between children, adolescents and young adults from disadvantaged versus advantaged socioeconomic circumstances. Specifically a difference of $-0.31(95 \% \mathrm{Cl}-0.51$ to -0.10$)$ litres in girls and -0.43 $(95 \% \mathrm{Cl}-0.51$ to -0.35$)$ litres in boys was observed. Conclusions Children, adolescents and young adults from disadvantaged socioeconomic circumstances had lower respiratory function, and boys presented higher respiratory health inequalities. This information contributes to explain the social patterning of respiratory diseases, and might enable health policy makers to tackle respiratory health inequalities at early ages.

\section{INTRODUCTION}

Disadvantaged socioeconomic circumstances have been associated with worse respiratory health outcomes, as for instance, underdeveloped lungs and a higher risk of respiratory disease in later life. ${ }^{1-3}$ Studies on adult and
Strengths and limitations of this study

- This study is the first systematic review and meta-analysis quantifying the magnitude of difference in respiratory function in early ages due to disadvantaged socioeconomic circumstances.

- It includes a broad literature search, screening and data extraction performed in duplicate, a firm study quality assessment and a comprehensive data analysis, including numerous sensitivity analysis.

- The review protocol has been developed in accordance with the Preferred Reporting Items for Systematic Review and Meta-analysis statement.

- The study limitations included the different estimates of forced expiratory volume in the first second presented in the studies and the high heterogeneity in the statistical analysis which also makes comparisons difficult. Nevertheless, we were able to perform the meta-analysis with two different estimates, showing that the effect size was quite similar independently of the estimate used.

older populations have demonstrated that individuals with lower socioeconomic position presented poorer respiratory function and a faster decline of lung volumes over time. ${ }^{3-5}$ Low social class was also previously associated with a reduction in forced expiratory volume in the first second $\left(\mathrm{FEV}_{1}\right)$ of more than $300 \mathrm{ml}$ among men, and more than $200 \mathrm{ml}$ among women. ${ }^{3}$

In the period from childhood to early adulthood, the association between socioeconomic circumstances and lung function has also been explored, ${ }^{6-10}$ and disadvantaged socioeconomic circumstances were associated with poorer lung function attainment. ${ }^{67}$ Growing evidence shows that childhood and adolescence constitute a critical time window for subsequent respiratory health ${ }^{11}$ for several reasons. First, in this period lungs are growing, ${ }^{12}$ and are highly susceptible to adverse influences, (eg, indoor and outdoor pollution, tobacco smoke, poor nutrition) 
which might restrain lung development, modulate respiratory function and induce airway diseases. ${ }^{3111314}$ Additionally, it is becoming evident that respiratory diseases have part of their origins in early childhood, ${ }^{15}$ thus tracking respiratory function since this period has the potential to detect early life differences in respiratory growth, which might be influenced by the social context and the social determinants of health. ${ }^{16}{ }^{17}$ Moreover, it has been demonstrated that lung volumes tend to increase from birth until early adulthood, ${ }^{12} 18$ therefore by studying this period we are able to assess inequalities in the maximal lung function attained.

Prior studies also suggest that there are sex differences in lung physiology and development, and these differences impact the incidence, susceptibility and severity of several lung diseases. ${ }^{19} 20$ Specifically in spirometry tests, the studies demonstrated that throughout childhood and adolescence, boys have 7\%-8\% larger lungs, but girls have faster lung rates (shorter expiratory time constants), judged from the $\mathrm{FEV}_{1}$ / forced vital capacity (FVC) ratio. ${ }^{121}$

Therefore, ascertaining the impact of early life socioeconomic circumstances on respiratory function is crucial to prevent uneven lung function growth among the different socioeconomic groups, which could result in unequal prevalence of respiratory diseases over the life course. Hence, this study aimed to systematically review the published evidence on the association between socioeconomic circumstances and respiratory function in children, adolescents and young adults, stratified by sex. Specifically, we aimed to assess the direction of this association, and to quantify its magnitude by conducting a meta-analysis, if possible, due to the nature of the studies.

\section{METHODS}

This systematic review and meta-analysis was performed and is reported in accordance with Preferred Reporting Items for Systematic Review and Meta-analysis (PRISMA) guidelines. $^{22}$

\section{Search strategy}

A search in Medline, ISI-Web of Science and Scopus was conducted from inception up to 22 January 2018. The search expression included numerous MESH terms and other relevant words and expressions ('Lung function' OR spirometry OR 'FEV1' OR 'Forced Expiratory Volume' OR 'Forced Vital Capacity' OR 'FVC' OR 'pulmonary function' OR 'respiratory function' OR 'total lung capacity' OR tlc) AND ('socioeconomic factors' OR 'socioeconomic position' OR 'social class' OR 'socioeconomic determinants' OR 'socioeconomic class' OR poverty OR education OR income OR occupation OR wealth OR deprivation OR overcrowding OR unemployment) AND (infant OR child* OR 'preschool child*' OR adolesc* OR youth OR teenager OR young OR 'young adult'). Further details on the search expression can be seen in (online supplementary table S1). Early life was considered the period from childhood to early adulthood, which also matches the period of lung growth. ${ }^{123}$ Evidence suggests that $\mathrm{FEV}_{1}$ and FVC keep increasing from birth till 25 years of age, that is, young adulthood, then remain stable for about 5-10 years, and start declining in later adulthood. ${ }^{12}$ Two researchers (Vânia Rocha and Sara Soares) independently screened all titles, abstracts and keywords, removed articles clearly failing to meet the inclusion criteria, and retrieved potentially eligible articles for fulltext review. The reference lists of the reviewed articles were also screened for potentially relevant articles that the electronic search failed to identify. Any disagreement between the researchers was sorted out by consulting a third investigator (Sílvia Fraga).

\section{Eligibility criteria}

The screening process occurred in three steps: first, articles were excluded based on title, abstract and keywords. In step 2, full texts of the articles were evaluated to determine eligibility based on previously defined criteria. And, in step 3, the selected articles were re-evaluated to determine their adequacy for data extraction. Therefore, during the whole screening process the investigators consecutively applied the following criteria to exclude studies: (1) That were not original peer-reviewed observational studies of the general population. (2) Not written in English, French, Portuguese or Spanish. (3) Not involving humans (eg, in vitro or animal studies). (4) That were review articles, editorials, methodological studies, conference or meeting abstracts, case reports or case studies, commentaries and letters or book chapters without original data. (5) With subjects older than 25 years. (6) That did not address respiratory function by different socioeconomic circumstances. (7) That did not report respiratory function with at least one spirometry value (eg, $\mathrm{FEV}_{1}$; FVC; ratio between $\mathrm{FEV}_{1}$ and $\mathrm{FVC}, \mathrm{FEV}_{1}$ / FVC; forced expiratory flow, FEF) by at least one socioeconomic indicator (ie, education, income, occupation, etc). (8) In which socioeconomic factors or respiratory function variables were just used for adjustments.

\section{Data extraction}

Data extraction was undertaken independently by the researchers in order to retrieve information on: authors and year; country; study design; sample size (total and number of subjects involved in the analysis of socioeconomic circumstances and respiratory function); female proportion; participants' age range or mean age with SD; information on diseases and/or respiratory symptoms; socioeconomic indicators; respiratory function indices, with the respective reference equations; and the relationship between socioeconomic circumstances and respiratory function indices.

\section{Quality assessment}

The risk of bias of each study was assessed independently by two reviewers using the Newcastle-Ottawa Scale (NOS).$^{24}$ For longitudinal studies, the original eight-item 
NOS for cohort studies was used to assess the three key areas of potential bias-selection of participants, comparability and measurements. For cross-sectional studies, only the relevant items were used assessing selection of participants, comparability and the associated factors. ${ }^{24} 25$ More details on the items assessed can be found in online supplementary text S1 and S2. The NOS for cohort studies ranges between zero and nine stars and for cross-sectional studies ranges between zero and six. Any disagreements between the two reviewers were resolved by discussion with a third investigator (Sílvia Fraga).

\section{Data analysis}

As summary measures, we extracted the direction of the association (eg, inexistent, positive or negative) and the magnitude of the association between the socioeconomic indicators and respiratory function indices. A positive association was considered when advantaged socioeconomic circumstances were associated with an increase in respiratory function or disadvantaged socioeconomic circumstances led to a decrease in respiratory function; a negative association was considered when advantaged socioeconomic circumstances were associated to a decrease in respiratory function or disadvantaged socioeconomic circumstances led to an increase in respiratory function.

Owing to the heterogeneity in the studies analyses, only articles that reported means and SD between advantaged and disadvantaged socioeconomic circumstances groups were brought forward into the meta-analysis. The estimates from articles reporting means and SD were transformed into standardised mean differences (SMDs) between advantaged and disadvantaged socioeconomic groups.

In the meta-analysis we also narrowed our focus to $\mathrm{FEV}_{1}$ measurements, as this respiratory function indicator has been the most widely reported and best understood index in the medical literature. ${ }^{12}$ Pooled SMDs and corresponding 95\% CIs were calculated by the DerSimonian-Laird method assuming a random-effects model, to account for both within-study and between-study variances. ${ }^{26}$ Between-study heterogeneity was quantified using I-squared $\left(\mathrm{I}^{2}\right)$ statistic. This statistic describes the percentage of variation across studies due to heterogeneity rather than chance. ${ }^{27}$ Visual inspection of the funnel plot, the Egger's regression asymmetry test and the Beggs' test were used for publication bias assessment. ${ }^{28} \mathrm{~A}$ broadly symmetrical plot indicated a lower risk of bias against the publication of negative results.

\section{Sensitivity analyses}

Sensitivity analyses were carried out in seven ways: (1) Applying a fixed-effects model, assuming an equal effect size across studies. (2) Conducting the meta-analysis including studies which reported the association between socioeconomic circumstances and lung function with $\beta$-coefficients from linear regression along with CIs, to test if the use of a different statistical measure would

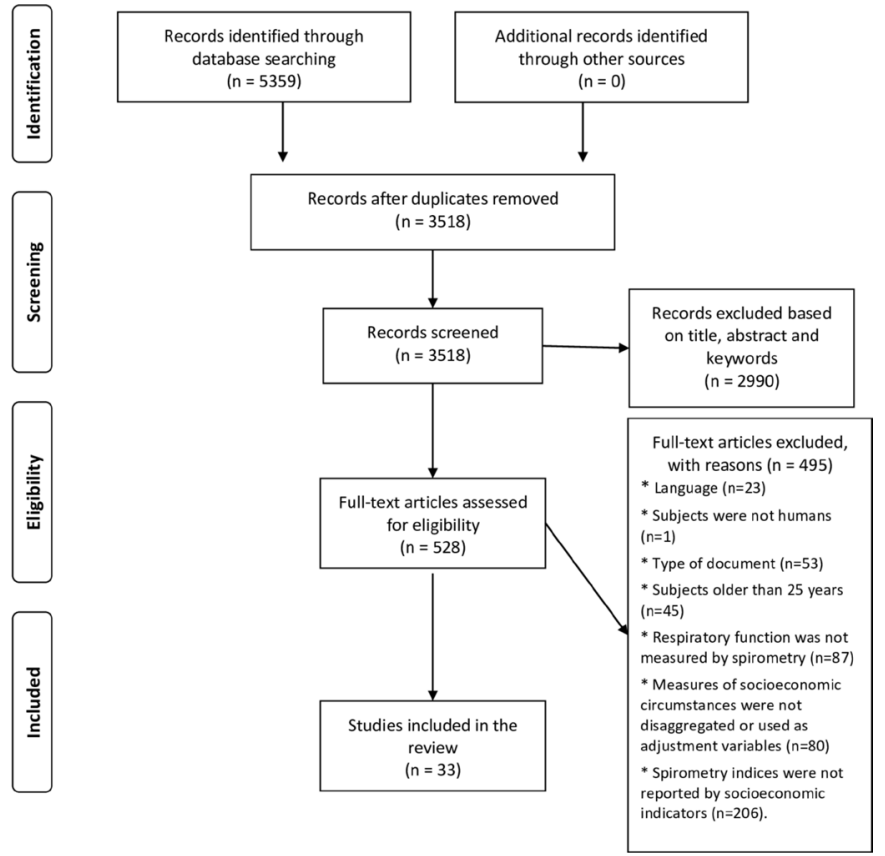

Figure 1 Preferred Reporting Items for Systematic Review and Meta-analysis (PRISMA) flow diagram of the literature search.

lead to different results. (3) Presenting the effect size by type of study. (4) Presenting the effect size by socioeconomic indicator. (5) Showing the effect size separately for healthy participants versus those who reported respiratory symptoms and diseases. (6) Showing the effect size separately for studies which presented adjusted values of $\mathrm{FEV}_{1}$ and those who did not perform adjustments. (7) Repeating the meta-analysis with each study removed sequentially. The analyses were carried out with STATA (V.11.0, StataCorp, College Station, Texas, USA).

\section{Patient and public involvement}

No patients were involved in this study, since we used data from previously published papers. However, this study aimed to raise awareness among the scientific community and policy makers on the effect of socioeconomic circumstances in respiratory function since the early ages, with a potential impact on respiratory health throughout the life course.

\section{RESULTS}

Figure 1 presents the literature search flow diagram. The systematic database search identified 5359 publications; after removing duplicates, the title, abstract and keywords were screened in 3308 papers. Five hundred and twenty-eight were full-text screened, and from these thirty-three papers were included. The reference list screening did not retrieve any additional manuscript. The results of the quality assessment with NOS showed that from the 33 papers included, only two papers ${ }^{29} 30$ had less than the median stars that can be attributed to each 
study, that is, scored as low quality (online supplementary table S2a,b).

Table 1 shows the characteristics of the included articles, 14 longitudinal and 19 cross-sectional studies. Samples sizes ranged from $77^{31}$ to $24010^{32}$ participants, and the majority of studies reported lung function results for both sexes together, with the exception of six studies ${ }^{6} 93-36$ that reported their findings separately for boys and girls, and one study ${ }^{37}$ that merely included girls. Participants' age ranged from 5 to 24 years old. Countries classified as high, upper-middle, lower-middle and low-income levels were included, and no significant differences were found between them. Most of the included studies were performed in high-income countries, as for example, USA ${ }^{9} 31323438-42$ or the UK, ${ }^{784-46}$ or a lowermiddle income country as India. ${ }^{35} 45$

From the 33 articles incorporated in this review, 27 used education as the socioeconomic indicator, or as part of an index of socioeconomic circumstances; reporting mainly both parents' education ${ }^{29} 313235-394447-51$ or the mothers' education. ${ }^{9} 37 \quad 40-42 \quad 46 \quad 52-54$ Occupation and income were reported in 12 studies, mainly as both parents' occupation 3035363844464753 and family or household income.

All the included studies reported estimates for $\mathrm{FEV}_{1}$, either as mean values of volume, ${ }^{69103035364648-505254}$ mean difference,${ }^{344446}$ percentages, ${ }^{29} 39$ percentage of predicted, ${ }^{31} 373840-434546515355$ percentage of change, ${ }^{7323356}$ z-scores, ${ }^{845}$ and/or the relation between $\mathrm{FEV}_{1}$ and FVC. 29303335374750

A positive association between the socioeconomic circumstances and the respiratory function indices was found in $23^{6729-31} 33-373941-46485051535456$ of the 33 articles, showing a reduced respiratory function in children, adolescents and young adults from disadvantaged socioeconomic circumstances, followed by no association observed in 9 studies, ${ }^{8932384047495255}$ and a negative association in 1 study. ${ }^{10}$

Figure 2 illustrates the meta-analysis of $\mathrm{SMD}$ in $\mathrm{FEV}_{1}$ between disadvantaged and advantaged socioeconomic groups by sex, including seven studies. ${ }^{630} 3536505457$ Overall, children, adolescents and young adults from disadvantaged socioeconomic circumstances presented a significantly lower $\mathrm{FEV}_{1}$ of -0.31 (95\% CI -0.42 to -0.21 ) litres when compared with those from advantaged socioeconomic circumstances. This trend was observed in both girls and boys, but the effect size was higher in boys (SMD $-0.43 ; 95 \% \mathrm{CI}-0.51$ to -0.35 litres). The $\mathrm{I}^{2}$ of the subanalysis in boys showed no heterogeneity $\left(\mathrm{I}^{2} 0.0 \%\right.$, $\mathrm{p}=0.664$ ), in contrast with the high heterogeneity between the studies of girls $\left(\mathrm{I}^{2} 71.2 \%, \mathrm{p}=0.002\right)$. The effect size for both sexes together was lower, being an SMD of -0.16 (95\% CI -0.24 to -0.08 ) litres between participants from disadvantaged versus advantaged socioeconomic circumstances. A funnel plot was computed to assess publication bias (figure 3), and its visual inspection did not indicate the presence of small-study effects. Egger's regression asymmetry test did not suggest significant small-study effects $(p=0.473)$ and Beggs' test also confirmed the absence of publication bias $(\mathrm{p}=0.458)$.

In the first sensitivity analysis, the use of a fixed-effects models slightly increased the pooled effect size in the meta-analysis (SMD $-0.34 ; 95 \%$ CI -0.38 to -0.29 litres) (online supplementary figure S1). Then, five further studies $^{710334256}$ were grouped into a meta-analysis of $\beta$-coefficients, showing that a decrease in one unit of socioeconomic circumstances leads to a reduction of -0.35 (-0.77 to 0.07$)$ litres in $\mathrm{FEV}_{1}$, which is very similar to the effect size found in the meta-analysis of the means and SD (online supplementary figure S2). Grouping studies by design had no influence on the pooled effect size and we observed that the effect sizes of the subanalysis were very similar in both cross-sectional $(-0.30 ; 95 \%$ CI -0.44 to -0.16 litres $)$ and longitudinal $(-0.33 ; 95 \%$ CI -0.52 to -0.14 litres) studies (online supplementary figure S3). Presenting the effect size by socioeconomic indicators had no influence on the pooled effect size, nevertheless it slightly reduced the heterogeneity in the subanalyses (online supplementary figure S4). We also observed that the effect size of socioeconomic disadvantage in $\mathrm{FEV}_{1}$ was almost double in participants with respiratory symptoms and diseases $(-0.44 ; 95 \% \mathrm{CI}-0.52$ to -0.36$)$ when compared with those without symptoms and diseases $(-0.24 ; 95 \%$ CI -0.37 to -0.10$)$ (online supplementary figure S5). Grouping studies by adjusted estimates or not showed a higher effect size in the group of studies with adjusted estimates $(-0.36 ; 95 \% \mathrm{CI}-0.51$ to -0.21 vs -0.25 ; $95 \%$ CI -0.42 to -0.09 ) (online supplementary figure S6). The adjustment variables were mainly age, sex, height and weight. Finally, excluding each study sequentially did not alter the final results (online supplementary figure S7).

\section{DISCUSSION}

This study systematically reviewed the evidence on the association between socioeconomic circumstances and respiratory function in children, adolescents and young adults considering sex differences. From the 33 papers included, 23 showed that disadvantaged socioeconomic circumstances were associated with lower respiratory function in early ages. In the meta-analysis, which included seven studies, we also found a mean difference of -0.31 litres in $\mathrm{FEV}_{1}$ between participants from disadvantaged versus advantaged socioeconomic circumstances, specifically a difference of -0.31 litres among girls and -0.43 litres among boys. To the best of our knowledge, this is the first meta-analysis to quantify the association between socioeconomic circumstances and respiratory function in children, adolescents and young adults, and results are close to the findings reported in a previous non-systematic review in adults, which showed a lower $\mathrm{FEV}_{1}$ of more than 0.2 litres among women and of more than 0.3 litres among men. ${ }^{3}$

Additionally, we observed that this difference was higher in boys, with boys of poorer socioeconomic circumstances presenting an overall difference of -0.43 litres in $\mathrm{FEV}_{1}$ 


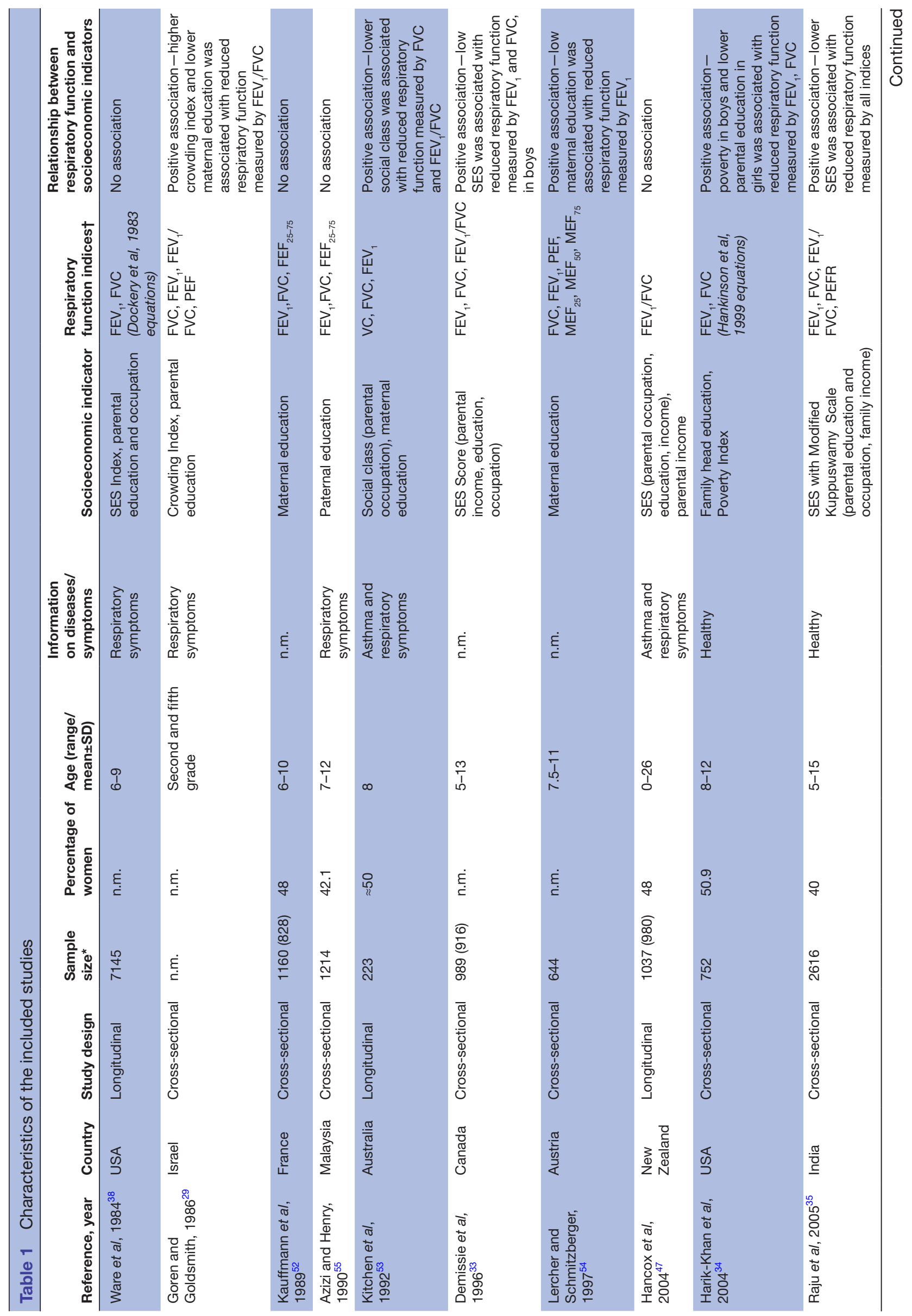

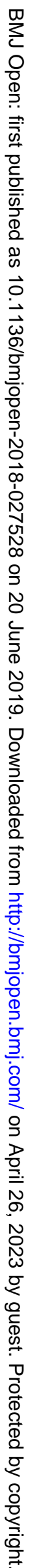




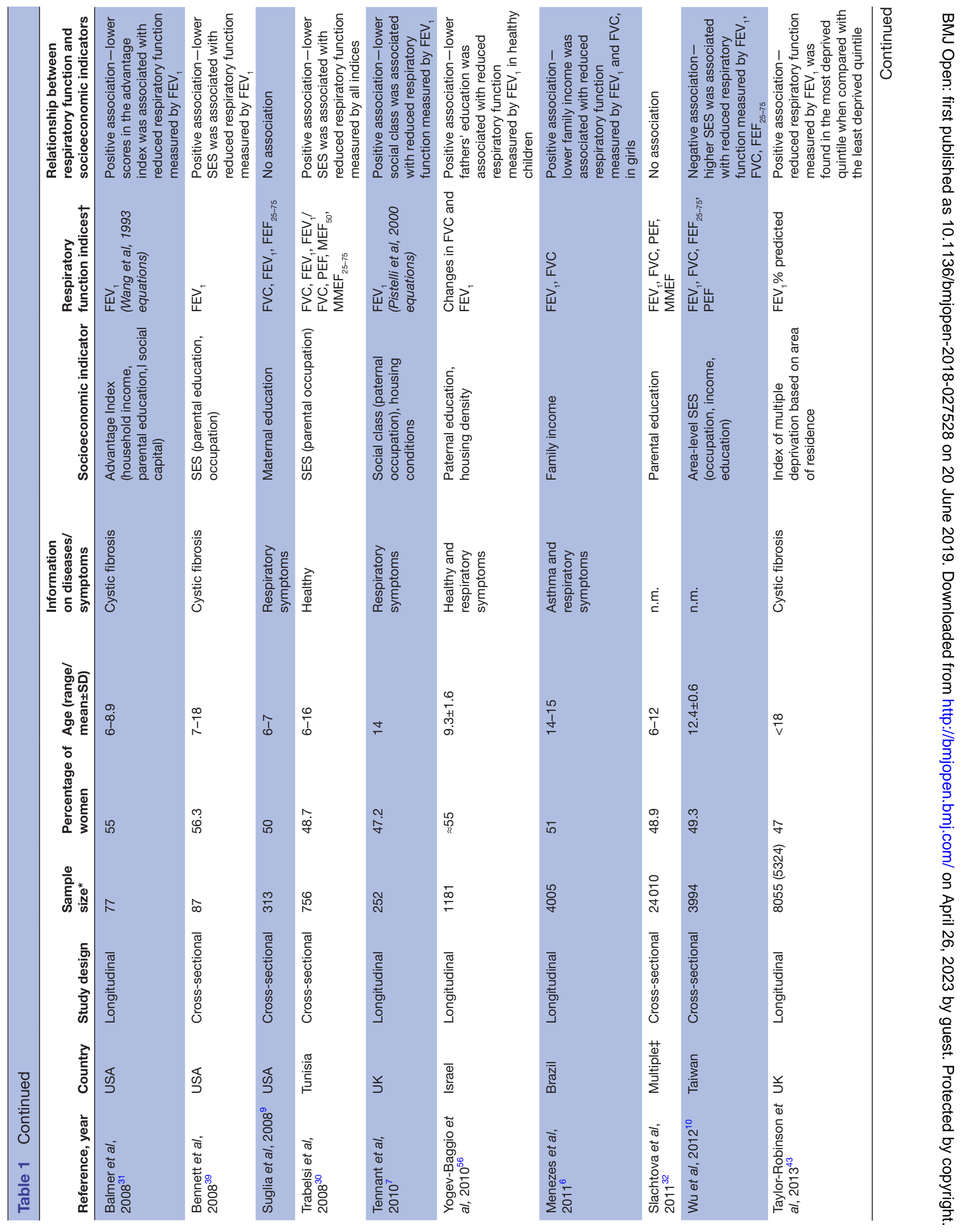




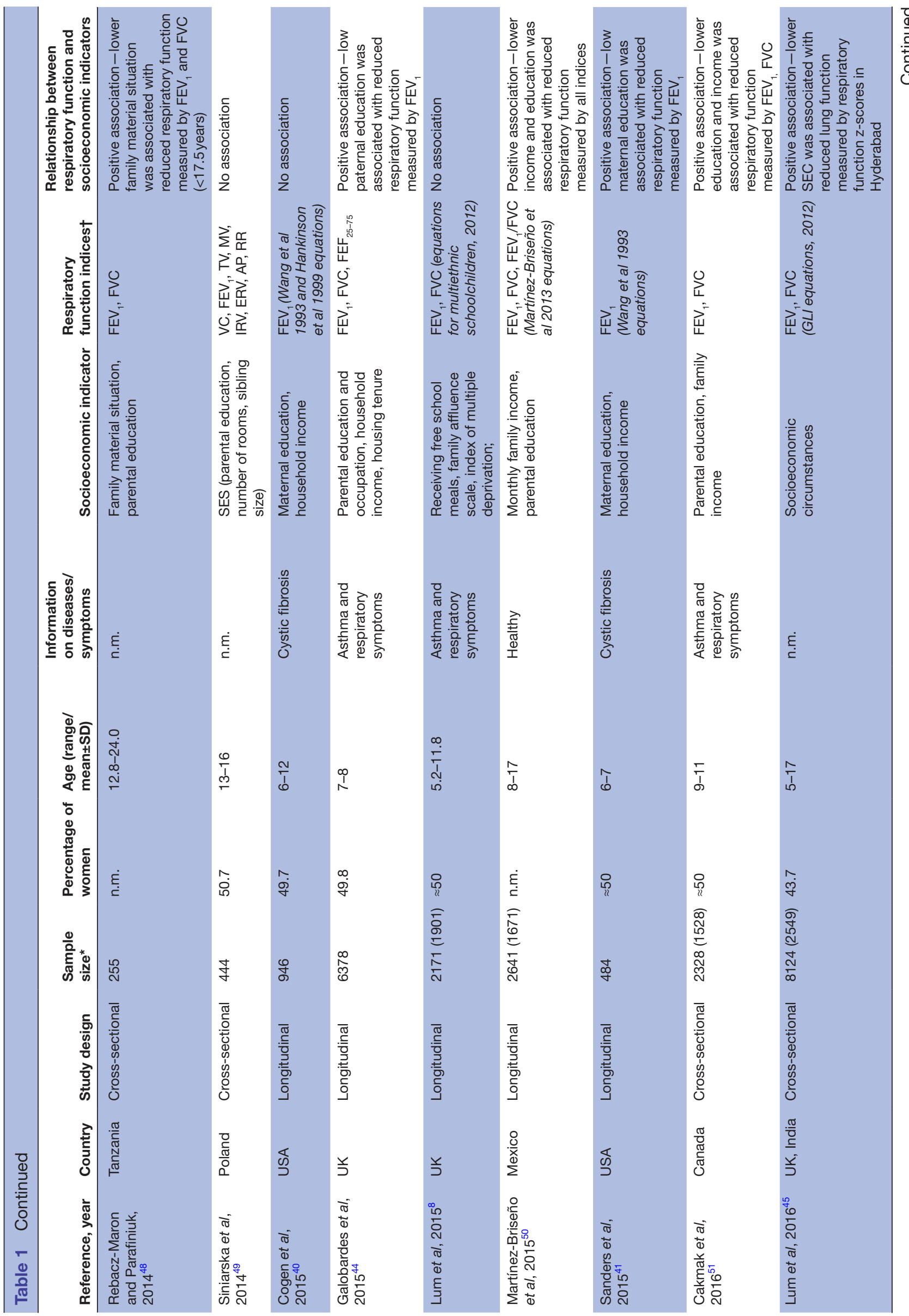

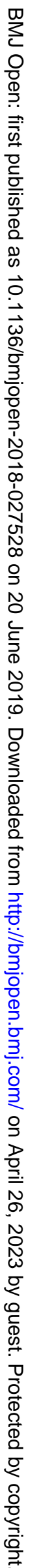




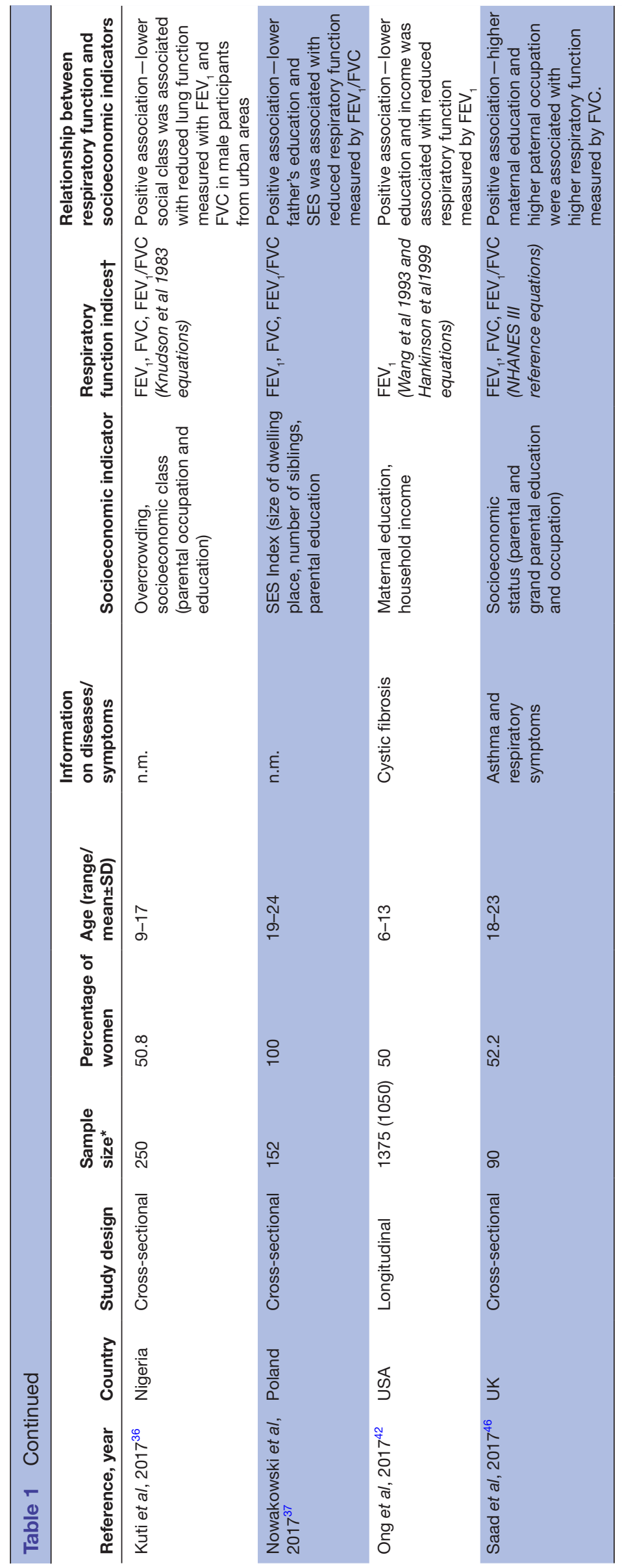

증

可跑

궁

政产焉

का

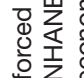

$0 \div \%$

14

نे

동 क्ष

崖安要

屯

施

융

ن

崖主

嵌

安

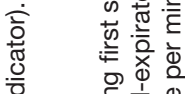

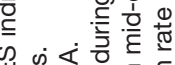

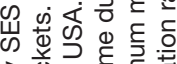

文遭

ه

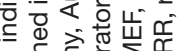

음 흘

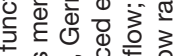

它.

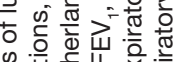

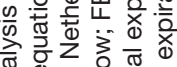

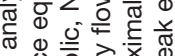

का

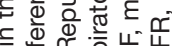

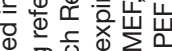

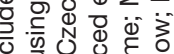

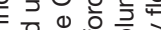

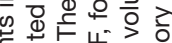

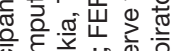

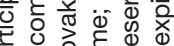

๙

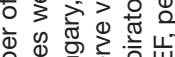

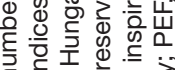

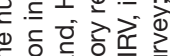

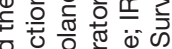

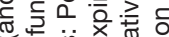

N

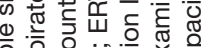

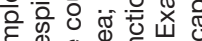

क्ष

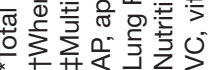




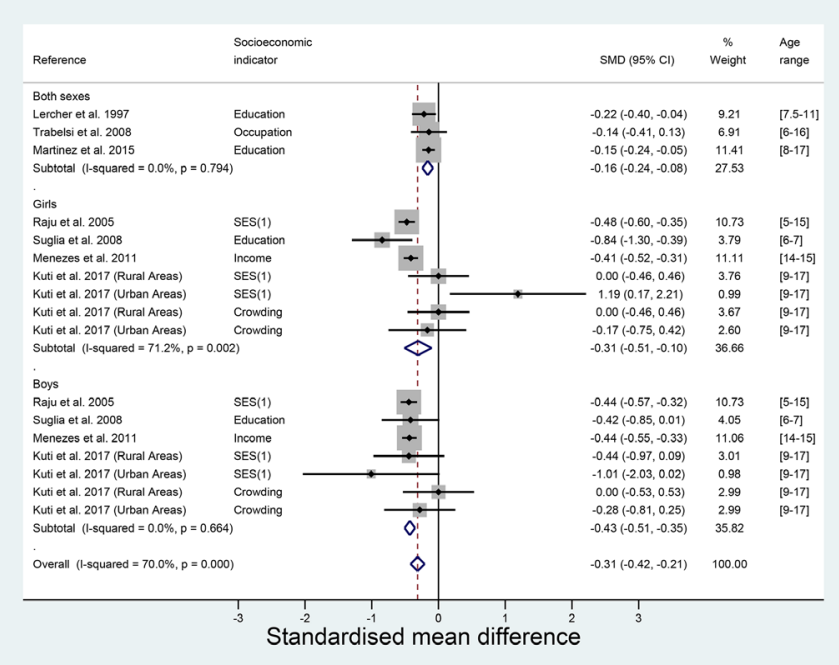

Figure 2 Forest plot of the meta-analysis of the standardised mean difference (SMD) in forced expiratory volume in the first second $\left(\mathrm{FEV}_{1}\right)$ between disadvantaged and advantaged socioeconomic groups, by sex. Note: Weights are from random effects analysis; SES(1): socioeconomic status classified using more than one socioeconomic indicator as education, occupation or/and income.

when compared with those of advantaged socioeconomic circumstances. Sex has previously been referred to as an important predictor of lung function, and standard morphometric methods confirmed that boys had larger lung size, more respiratory bronchioles and wider airway diameters compared with girls of the same age and stature, which explains their increased lung volumes. ${ }^{125859}$ However these anthropometric differences were not enough to clarify the differences found between boys from different socioeconomic circumstances. There is some prior evidence showing that socioeconomic inequalities in health, including outcomes of respiratory development and disease, are more pronounced in men of different age groups. ${ }^{192060}$ Several explanations

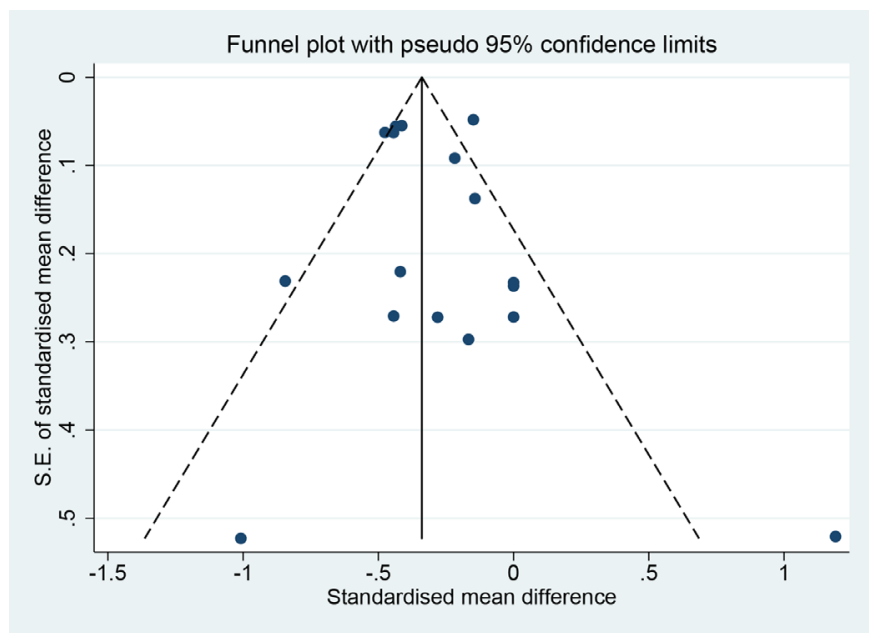

Figure 3 Funnel plot from the meta-analysis of forced expiratory volume in the first second by socioeconomic circumstances. have been proposed, either showing that with regards to health outcomes men are more sensitive to socioeconomic inequalities between groups, ${ }^{60}$ or supporting the existence of biological and anatomical differences between men and women which lead to differences in lung function between the sexes. ${ }^{196162}$ Prior studies have reported that since the prenatal period lung maturation is more advanced in female fetuses than in the male, ${ }^{61}$ that lung growth during adolescence is faster in girls than in boys, ${ }^{62}$ or that the prevalence of respiratory diseases in childhood, for instance asthma and allergic rhinitis, is higher in boys. ${ }^{19}$ All these hypotheses may help explain differences between boys and girls even at early ages; nevertheless further studies are needed to investigate this tendency. Sex differences seem to play an important role in both healthy and diseased lungs from very early life, ${ }^{19}$ and considering these differences in epidemiological studies might be imperative to obtain reliable estimates on respiratory health inequalities.

$\mathrm{FEV}_{1}$ has been the most widely reported index of respiratory function in the included studies. This finding confirmed previous evidence ${ }^{1263}$ suggesting that $\mathrm{FEV}_{1}$ is by far the most reported index in medical literature as it provides information on airflow based on airway calibre and elasticity. ${ }^{64}$ Moreover, it allows determine $\mathrm{FEV}_{1} /$ FVC ratio, which is used to detect the presence of airway obstruction and to diagnose respiratory diseases. ${ }^{65}$ Indeed, spirometry has been used as a pivotal screening test of general respiratory health, as it is simple, non-invasive, relatively inexpensive, and can provide information with the potential to prevent, identify and quantify respiratory diseases. ${ }^{6366}$ Nevertheless, we also observed that spirometry assessment has been mostly directed to specific populations, such as patients with respiratory symptoms, ${ }^{729385557}$ asthma ${ }^{6844475153}$ or cystic fibrosis, ${ }^{31} 39-43$ and its use in healthy children and adolescents $^{3034355056}$ to monitor lung growth has been less explored. In fact, our sensitivity analysis confirmed that the effect of disadvantaged socioeconomic circumstances in participants with respiratory symptoms and disease are almost double compared with the effect on healthy participants, supporting the need for respiratory screening and continuous monitoring of these populations. However, evidence showed that the two respiratory diseases with the largest burden on patients and on society (asthma and chronic obstructive pulmonary disease) have part of their origins in early life $\mathrm{e}^{1567}$ and tracking respiratory function in healthy children since this period might also have potential to detect early life differences in respiratory growth and in the maximal lung function attainment at early adulthood with clinical significance for future respiratory diseases.

Education, occupation and income were the most used socioeconomic indicators associated with respiratory function. These three indicators have been extensively referred to as most common to characterise socioeconomic position and to describe and evaluate health inequalities, ${ }^{68-70}$ as single indicators ${ }^{442}$ or as combination 
into SES indexes. ${ }^{35} 47$ Even though using different socioeconomic indicators may result in gradients of varying slopes, no single best socioeconomic indicator is suitable for all study aims and each indicator may be more or less relevant to the different health outcomes at different stages of the life course. ${ }^{71}$ The SES indexes are intended to incorporate and therefore to adjust for different aspects of socioeconomic position but the effect from each single indicator remains unknown. ${ }^{71} \mathrm{~A}$ single measure will not encompass the entire effect of socioeconomic circumstances on health, but it might be most appropriate for understanding the specific mechanisms of socioeconomic inequalities in health. ${ }^{71}$ In fact, education was one of the most reported SES indicator, as either parents' education or maternal education. Maternal education is a good example of how socioeconomic factors might have an indirect effect on respiratory function, as previous studies have shown, this indicator is highly correlated with the nurture provided to the children, either by ensuring adequate nutritional intake, ${ }^{72}{ }^{73}$ which influences lung growth, or by avoiding health risk factors (eg, smoking during pregnancy or passive smoking, physical inactivity, etc) ${ }^{74}$ with immediate or long-term consequences on respiratory health.

Additionally, maternal education was associated with children's height for age, ${ }^{75}$ which is related with respiratory function; ${ }^{67677}$ however only $13^{68-1032} 333546495254-56$ of the 33 included studies made adjustments for height. Therefore this study is an alert to the need for considering height when assessing lung function since higher height is associated with larger lung capacity, ${ }^{78}$ and there is evidence that height is strongly socially patterned since childhood. ${ }^{75}$ Age and sex are also important determinants of lung volumes and capacities. ${ }^{58}$ However, only 13 studies $^{6-8} 10324244464750555679$ adjusted for sex and 15 adjusted for age. ${ }^{6} 10293233414244464750525456$ These results were in line with our sensitivity analysis comparing studies with and without adjusted estimates that showed a higher effect size in the group of studies with adjusted estimates. Age, sex and height, considered the main predictors of lung function, were the more frequent adjustment variables, following previously established guidelines recommending that spirometry indices should account for these predictors to increase accuracy and reduce biased estimations. $^{1280}$

Other limitations should be acknowledged. The interpretation of spirometry results is also largely dependent on the use of appropriate reference values, ${ }^{65}$ which was only mentioned by about a third (12 in 33) of the included studies. The high variability in the indicators of socioeconomic position reduced the power to detect statistically significant differences, making comparisons difficult. To address this issue we did a sensitivity analysis grouping studies by socioeconomic indicators, however, these results showed that grouping studies by these indicators would not influence the overall pooled effect size, although it slightly reduced heterogeneity in subanalyses. The different estimates of $\mathrm{FEV}_{1}$ presented in the studies (mean values, predicted values, percentages, z-scores) and the high heterogeneity in the statistical analysis make it difficult to compare studies, introducing a potential source of selection bias where only studies with extractable and comparable results are included in the meta-analysis. We addressed this in two ways, first by contacting authors for further data; and then by assessing publication bias with visual inspection of funnel plots and Egger's and Beggs' tests, which confirmed the absence of publication bias. Moreover, computing the meta-analysis with a different statistical measure ( $\beta$-coefficients) showed a very similar result.

The studies included in both qualitative and quantitative syntheses mainly had a cross-sectional design $(n=19)$ rather than longitudinal $(n=14)$. We could expect that studies with longitudinal designs would show higher effects of disadvantaged socioeconomic circumstances in lung function since these studies collected data over time and are more appropriate to assess causal relationships; nevertheless, the effect sizes by type of study were quite similar for both cross-sectional and longitudinal studies. Moreover, as the exposure and the outcome are both measured in early ages, we hypothesise that the effects are not yet completed established, and perhaps if the outcome was measured during adulthood the differences would be more pronounced.

Finally, the reporting quality of the included articles should be considered. Nevertheless, only two articles were scored as low quality, having less than three stars in a maximum of six for cross-sectional studies. Therefore, we did not expect that the quality of articles had relevant implications in our conclusions.

\section{CONCLUSIONS}

This systematic review and meta-analysis shows that children, adolescents and young adults from disadvantaged socioeconomic circumstances presented lower respiratory function, and respiratory health inequalities are higher among boys. These results highlight the implications of early disadvantaged socioeconomic circumstances for respiratory health. This evidence also contributes to explain the social patterning of respiratory diseases during adulthood and at older ages, and might enable health policy makers to tackle respiratory health inequalities at early ages.

Contributors Vânia Rocha contributed to the study conceptualisation, conducted the literature search, data analysis and interpretation, and drafted the manuscript. Sara Soares conducted the literature search and data analysis. Silvia Stringhini contributed to data analysis, interpretation and critical revision. Sílvia Fraga performed the study conceptualisation, contributed to data analysis, interpretation, critical revision and editing of the review. All authors approved the final manuscript as submitted and agree to be accountable for all aspects of the work.

Funding This work was supported by FEDER through the Operational Programme Competitiveness and Internationalization and national funding from the Foundation for Science and Technology (FCT; Portuguese Ministry of Science, Technology and Higher Education) under the EPIUnit, Instituto de Saúde Pública da Universidade do Porto, Portugal (POCl-01-0145-FEDER-006862; Reference: UID/DTP/04750/2013) and within the projects "How childhood social adversity 
shapes health: The biology of social adversity" (POCI-01-0145-FEDER-016838; Reference: PTDC/DTP-EPI/1687/2014) and "When do health inequalities start? Understanding the impact of childhood social adversity on health trajectories from birth to early adolescence" (POCl-01-0145-FEDER-029567; Reference: PTDC/ SAU PUB/29567/2017). It is also supported by the LIFEPATH Consortium (Horizon 2020 grant $n^{\circ}$ 633666), the FCT PhD grants SFRH/BD/103726/2014 (Vânia Rocha) and SFRH/BD/108742/2015 (Sara Soares), and the FCT Investigator contracts DL57/2016/CP1356/CT0001 (Sílvia Fraga) co-funded by the FCT and the POCH/FSE Programme.

Competing interests None declared.

Patient consent for publication Not required

Provenance and peer review Not commissioned; externally peer reviewed.

Data sharing statement Extracted data are available upon request to the corresponding author.

Open access This is an open access article distributed in accordance with the Creative Commons Attribution Non Commercial (CC BY-NC 4.0) license, which permits others to distribute, remix, adapt, build upon this work non-commercially, and license their derivative works on different terms, provided the original work is properly cited, appropriate credit is given, any changes made indicated, and the use is non-commercial. See: http://creativecommons.org/licenses/by-nc/4.0/.

\section{REFERENCES}

1. The Lancet Respiratory Medicine. Health inequality: a major driver of respiratory disease. Lancet Respir Med 2017;5:235.

2. Ellison-Loschmann L, Sunyer J, Plana E, et al. Socioeconomic status, asthma and chronic bronchitis in a large community-based study. Eur Respir J 2007;29:897-905.

3. Hegewald MJ, Crapo RO. Socioeconomic status and lung function. Chest 2007;132:1608-14

4. Tabak C, Spijkerman AM, Verschuren WM, et al. Does educational level influence lung function decline (Doetinchem Cohort Study)? Eur Respir J 2009;34:940-7.

5. Gaffney AW, Hang JQ, Lee MS, et al. Socioeconomic status is associated with reduced lung function in China: an analysis from a large cross-sectional study in Shanghai. BMC Public Health 2016;16:96

6. Menezes AM, Dumith SC, Perez-Padilla R, et al. Socioeconomic trajectory from birth to adolescence and lung function: prospective birth cohort study. BMC Public Health 2011;11:596.

7. Tennant PW, Gibson GJ, Parker L, et al. Childhood respiratory illness and lung function at ages 14 and 50 years: childhood respiratory illness and lung function. Chest 2010;137:146-55.

8. Lum S, Bountziouka V, Sonnappa S, et al. Lung function in children in relation to ethnicity, physique and socioeconomic factors. Eur Respir J 2015;46:1662-71.

9. Suglia SF, Ryan L, Laden F, et al. Violence exposure, a chronic psychosocial stressor, and childhood lung function. Psychosom Med 2008;70:160-9.

10. Wu YF, Wu CK, Chen DR, et al. Association of area socioeconomic status with lung function in children. Prev Med 2012:55:644-9.

11. Dratva J, Zemp E, Dharmage SC, et al. Early life origins of lung ageing: early life exposures and lung function decline in adulthood in two european cohorts aged $28-73$ years. PLoS One 2016;11:e0145127.

12. Quanjer $\mathrm{PH}$, Stanojevic S, Stocks J, et al. Changes in the FEV $\mathrm{FV}_{1} / \mathrm{FV}$ ratio during childhood and adolescence: an intercontinental study. Eur Respir J 2010;36:1391-9.

13. Apostol GG, Jacobs DR, Tsai AW, et al. Early life factors contribute to the decrease in lung function between ages 18 and 40. Am J Respir Crit Care Med 2002;166:166-72.

14. Liao SY, Lin X, Christiani DC. Occupational exposures and longitudinal lung function decline. Am J Ind Med 2015;58:14-20.

15. Cukic V, Lovre V, Dragisic D, et al. Asthma and Chronic Obstructive Pulmonary Disease (COPD) - differences and similarities. Mater Sociomed 2012;24:100-5.

16. Williams DR, Sternthal M, Wright RJ. Social determinants: taking the social context of asthma seriously. Pediatrics 2009;123:S174-S184.

17. Stocks J, Sonnappa S. Early life influences on the development of chronic obstructive pulmonary disease. Ther Adv Respir Dis 2013;7:161-73

18. Melén E, Guerra S. Recent advances in understanding lung function development. F1000Res 2017;6:726.

19. Carey MA, Card JW, Voltz JW, et al. It's all about sex: male-female differences in lung development and disease. Trends Endocrinol Metab 2007;18:308-13.
20. Matthews S, Manor O, Power C. Social inequalities in health: are there gender differences? Soc Sci Med 1999;48:49-60.

21. Merkus PJ, ten Have-Opbroek AA, Quanjer PH. Human lung growth: a review. Pediatr Pulmonol 1996;21:383-97.

22. Moher D, Liberati A, Tetzlaff J, et al. Preferred reporting items for systematic reviews and meta-analyses: the PRISMA statement. Ann Intern Med 2009;151:264-9.

23. Berry CE, Billheimer D, Jenkins IC, et al. A distinct low lung function trajectory from childhood to the fourth decade of life. Am J Respir Crit Care Med 2016;194:607-12.

24. Wells GA, Shea B, O'Connell D, et al. The Newcastle-Ottawa Scale (NOS) for assessing the quality of nonrandomised studies in metaanalyses. http://www.ohri.ca/programs/clinical_epidemiology/oxford. asp (Accessed 15 Oct 2018).

25. Lee CS, Liew TM. Inappropriate prescribing among older persons in primary care: protocol for systematic review and meta-analysis of observational studies. BMJ Open 2017;7:e015395.

26. Harris RJ, Deeks JJ, Altman DG, et al. Metan: fixed- and randomeffects meta-analysis. Stata J 2008;8:3-28.

27. Higgins JP, Thompson SG. Quantifying heterogeneity in a metaanalysis. Stat Med 2002;21:1539-58.

28. Sterne JAC, Gavaghan D, Egger M. Publication and related bias in meta-analysis. J Clin Epidemiol 2000;53:1119-29.

29. Goren Al, Goldsmith JR. Epidemiology of childhood respiratory disease in Israel. Eur J Epidemiol 1986;2:139-50.

30. Trabelsi Y, Pariès J, Harrabi I, et al. Factors affecting the development of lung function in Tunisian children. Am J Hum Biol 2008;20:716-25.

31. Balmer DF, Schall JI, Stallings VA. Social disadvantage predicts growth outcomes in preadolescent children with cystic fibrosis. $J$ Cyst Fibros 2008;7:543-50.

32. Slachtova H, Gehring U, Hoek G, et al. Parental education and lung function of children in the PATY study. Eur J Epidemiol 2011;26:45-54

33. Demissie K, Ernst P, Hanley JA, et al. Socioeconomic status and lung function among primary school children in Canada. Am J Respir Crit Care Med 1996;153:719-23.

34. Harik-Khan RI, Muller DC, Wise RA. Racial difference in lung function in African-American and White children: effect of anthropometric, socioeconomic, nutritional, and environmental factors. Am J Epidemiol 2004;160:893-900.

35. Raju PS, Prasad KV, Ramana YV, et al. Influence of socioeconomic status on lung function and prediction equations in Indian children. Pediatr Pulmonol 2005;39:528-36.

36. Kuti BP, Oladimeji Ol, Kuti DK, et al. Rural-urban disparity in lung function parameters of Nigerian children: effects of socio-economic, nutritional and housing factors. Pan Afr Med J 2017;28.

37. Nowakowski D, Kliś K Żurawiecka $\mathrm{M}$, et al. Influence of socioeconomic and anthropometric factors on respiratory function in female university students. Adv Exp Med Biol 2017;968:41-48.

38. Ware JH, Dockery DW, Spiro A, et al. Passive smoking, gas cooking, and respiratory health of children living in six cities. Am Rev Respir Dis 1984:129:366-74.

39. Bennett DS, Snooks Q, Llera S, et al. Monitoring and internalizing symptoms among youths with cystic fibrosis. J Child Health Care 2008;37:278-92.

40. Cogen J, Emerson J, Sanders DB, et al. Risk factors for lung function decline in a large cohort of young cystic fibrosis patients. Pediatr Pulmonol 2015;50:763-70.

41. Sanders DB, Emerson J, Ren CL, et al. Early childhood risk factors for decreased FEV1 at age six to seven years in young children with cystic fibrosis. Ann Am Thorac Soc 2015;12:1170-6.

42. Ong T, Schechter M, Yang J, et al. Socioeconomic status, smoke exposure, and health outcomes in young children with cystic fibrosis. Pediatrics 2017;139:e20162730.

43. Taylor-Robinson DC, Smyth RL, Diggle PJ, et al. The effect of social deprivation on clinical outcomes and the use of treatments in the UK cystic fibrosis population: a longitudinal study. Lancet Respir Med 2013;1:121-8.

44. Galobardes B, Granell R, Sterne J, et al. Childhood wheezing, asthma, allergy, atopy, and lung function: different socioeconomic patterns for different phenotypes. Am J Epidemiol 2015;182:763-74.

45. Lum S, Bountziouka V, Quanjer P, et al. Challenges in collating spirometry reference data for South-Asian children: an observational study. PLoS One 2016;11:e0154336.

46. Saad NJ, Patel J, Minelli C, et al. Explaining ethnic disparities in lung function among young adults: a pilot investigation. PLOS One 2017;12:e0178962.

47. Hancox RJ, Milne BJ, Taylor DR, et al. Relationship between socioeconomic status and asthma: a longitudinal cohort study. Thorax 2004:59:376-80. 
48. Rębacz-Maron E, Parafiniuk M. Spirometry results (FEV1 and FVC) in young Bantu men from Tanzania vs environmental and family characteristics. Ann Hum Biol 2014;41:15-22.

49. Siniarska A, Strzyzewska D, Koziel S. Variation in indicators of respiratory functions among Warsaw adolescents in relation to ambient air pollution and smoking. Coll Antropol 2014;38:195-200.

50. Martínez-Briseño D, Fernández-Plata R, Gochicoa-Rangel L, et al. Socioeconomic status and longitudinal lung function of healthy mexican children. PLoS One 2015;10:e0136935.

51. Cakmak S, Hebbern C, Cakmak JD, et al. The modifying effect of socioeconomic status on the relationship between traffic, air pollution and respiratory health in elementary schoolchildren. $J$ Environ Manage 2016;177:1-8.

52. Kauffmann F, Tager IB, Muñoz A, et al. Familial factors related to lung function in children aged 6-10 years. Results from the PAARC epidemiologic study. Am J Epidemiol 1989;129:1289-99.

53. Kitchen WH, Olinsky A, Doyle LW, et al. Respiratory health and lung function in 8-year-old children of very low birth weight: a cohort study. Pediatrics 1992;89(6 Pt 2):1151-8.

54. Lercher P, Schmitzberger R. Birth weight, education, environment, and lung function at school age: a community study in an alpine area. Eur Respir J 1997;10:2502-7.

55. Azizi BH, Henry RL. Effects of indoor air pollution on lung function of primary school children in Kuala Lumpur. Pediatr Pulmonol 1990;9:24-9.

56. Yogev-Baggio T, Bibi H, Dubnov J, et al. Who is affected more by air pollution-sick or healthy? Some evidence from a health survey of schoolchildren living in the vicinity of a coal-fired power plant in Northern Israel. Health Place 2010;16:399-408.

57. Franco Suglia S, Gryparis A, Schwartz J, et al. Association between traffic-related black carbon exposure and lung function among urban women. Environ Health Perspect 2008;116:1333-7.

58. Lutfi MF. The physiological basis and clinical significance of lung volume measurements. Multidiscip Respir Med 2017;12:3.

59. Thurlbeck WM. Postnatal human lung growth. Thorax 1982;37:564-71.

60. Mustard CA, Etches J. Gender differences in socioeconomic inequality in mortality. J Epidemiol Community Health 2003;57:974-80.

61. LoMauro A, Aliverti A. Sex differences in respiratory function. Breathe 2018;14:131-40.

62. Hibbert M, Lannigan A, Raven J, et al. Gender differences in lung growth. Pediatr Pulmonol 1995;19:129-34.

63. Miller MR, Hankinson J, Brusasco V, et al. Standardisation of spirometry. Eur Respir J 2005;26:319-38.

64. Piccioni P, Tassinari R, Carosso A, et al. Lung function changes from childhood to adolescence: a seven-year follow-up study. BMC Pulm Med 2015;15:31.

65. Brazzale D, Hall G, Swanney MP. Reference values for spirometry and their use in test interpretation: a position Statement from the Australian and New Zealand Society of Respiratory Science. Respirology 2016;21:1201-9.

66. Hnizdo E, Glindmeyer HW, Petsonk EL. Workplace spirometry monitoring for respiratory disease prevention: a methods review. Int J Tuberc Lung Dis 2010;14:796-805.

67. Carraro S, Scheltema N, Bont L, et al. Early-life origins of chronic respiratory diseases: understanding and promoting healthy ageing. Eur Respir J 2014;44:1682-96.

68. Galobardes B, Lynch J, Smith GD. Measuring socioeconomic position in health research. Br Med Bull 2007;81-82:21-37.

69. Arcaya MC, Arcaya AL, Subramanian SV. Inequalities in health: definitions, concepts, and theories. Glob Health Action 2015;8:27106.

70. Daly MC, Duncan GJ, McDonough P, et al. Optimal indicators of socioeconomic status for health research. Am J Public Health 2002;92:1151-7.

71. Galobardes B, Shaw M, Lawlor DA, et al. Indicators of socioeconomic position (part 1). J Epidemiol Community Health 2006;60:7-12.

72. van Ansem WJ, Schrijvers CT, Rodenburg G, et al. Maternal educational level and children's healthy eating behaviour: role of the home food environment (cross-sectional results from the INPACT study). Int J Behav Nutr Phys Act 2014;11:113.

73. Lakshman R, Zhang J, Zhang J, et al. Higher maternal education is associated with favourable growth of young children in different countries. J Epidemiol Community Health 2013;67:595-602.

74. Güneș PM. The role of maternal education in child health: evidence from a compulsory schooling law. Econ Educ Rev 2015;47:1-16.

75. Howe LD, Tilling K, Galobardes B, et al. Socioeconomic differences in childhood growth trajectories: at what age do height inequalities emerge? J Epidemiol Community Health 2012;66:143-8.

76. Desai S, Alva S. Maternal education and child health: is there a strong causal relationship? Demography 1998;35:71-81.

77. Gray LA, Leyland AH, Benzeval M, et al. Explaining the social patterning of lung function in adulthood at different ages: the roles of childhood precursors, health behaviours and environmental factors. $J$ Epidemiol Community Health 2013;67:905-11.

78. Gunnell D, Whitley E, Upton MN, et al. Associations of height, leg length, and lung function with cardiovascular risk factors in the Midspan Family Study. J Epidemiol Community Health 2003;57:141-6.

79. Taylor-Robinson DC, Smyth R, Diggle PJ, et al. A longitudinal study of the impact of social deprivation and disease severity on employment status in the UK cystic fibrosis population. PLoS One 2013;8:e73322.

80. Quanjer PH, Stanojevic S, Cole TJ, et al. Multi-ethnic reference values for spirometry for the 3-95-yr age range: the global lung function 2012 equations. 2012;40:1324. 